\title{
UN ANÁLISIS DE POLÍTICAS DE CONSUMO ALIMENTARIO EN EQUILIBRIO PARCIAL Y EQUILIBRIO GENERAL*
}

\author{
NorA LUSTIG
}

El Colegio de México

\section{INTRODUCCIÓN}

EN TRABAJOS ANTERIORES HEMOS ANALIZADO la relación entre distribución del ingreso y patrones y niveles de consumo alimentario, con base en la Encuesta de Ingresos y Gastos de los Hogares de 1977 (SPP) (véase Lustig 1982a y 1982b). Entre las principales conclusiones de estos trabajos, resalta la de haber encontrado que los hogares que percibieron un ingreso inferior al salario mínimo (alrededor de $45 \%$ del total), no alcanzaban a gastar en alimentos un monto equivalente al costo de la Canasta Básica Recomendable, elaborada por el Sistema Alimentario Mexicano, 1980, esto sucede a pesar de que destinan cerca de $56 \%$ de su gasto total a este rubro (Lustig, 1982a:54).

Por otra parte, se observó que, de no mediar un proceso redistributivo (es decir, suponiendo una distribución del ingreso igual a la de

* El modelo de equilibrio general utilizado en este trabajo fue realizado con la colaboración de Bill Gibson y Lance Taylor. Agradezco a Cassio Luiselli, Antonio Martín del Campo y Lance Taylor sus comentarios a una versión anterior del trabajo. Quiero señalar la constante y valiosa ayuda de Ernesto Linares. 
1977), los deciles más bajos tendrían que esperar entre dos y tres generaciones para alcanzar un ingreso equivalente al salario mínimo de 1977 , si el ingreso nacional per cápita creciera uniformemente $3 \%$ (ibid.:243).

En otro estudio emprendimos la tarea de calcular el costo fiscal de algunas de las medidas que se pueden adoptar para aumentar el consumo de alimentos (Lustig, 1982). Las medidas que se analizaron incluyen cupones de compra, precios subsidiados (generalizados y discriminatorios) y transferencias de ingresos. Se encontró que, en términos del costo fiscal, los cupones de compra resultan la opción más eficiente, $y$ en segundo lugar, el subsidio a precios discriminatorio. ${ }^{1}$ Por otra parte, un subsidio a precios generalizado resulta ser la opción más cara de todas; adicionalmente, esta medida es regresiva desde el punto de vista distributivo, porque beneficia también a quienes no lo necesitan. No obstante su costo, esta última es la medida más usada, dada la facilidad para ponerla en práctica.

El cálculo del costo fiscal se hizo mediante una metodología de equilibrio parcial. ${ }^{2}$ Es de todos conocido que una visión de equilibrio parcial puede dejar fuera elementos que, cuando se ven en un contexto de equilibrio general, alteran los resultados obtenidos del enfoque parcial. Por ello, aquí hemos emprendido una comparación de ambos métodos para calcular los efectos de una transferencia de ingresos y de un subsidio a los precios (discriminatorio y generalizado).

El método de equilibrio parcial nos permite calcular exclusivamente el costo fiscal asociado a cada una de las medidas. En el equilibrio general podremos observar, además de dicho costo, los efectos sobre la balanza de pagos, la distribución y niveles del ingreso y el consumo, y el nivel de actividad y empleo.

$\mathrm{El}$ análisis de equilibrio general se hace con base en un modelo multisectorial de la economía mexicana. Este modelo es de corto plazo y de ajuste keynesiano: la inversión y las exportaciones están dadas en términos reales, y el nivel de ahorro se ajusta a través de dos mecanismos: cambios en el nivel de actividad (ajuste típicamente keynesiano), y cambios en la distribución del ingreso (ajustes del tipo introducido por Kalecki y Kaldor).

1 Sin embargo, el beneficio de una transferencia es mayor para el receptor porque, además de aumentar el consumo de alimentos, también puede aumentar el de otros bienes, a los mismos precios relativos.

2 La descripción del cálculo de los costos fiscales de cada tipo de medida se presenta más ađelante; véase también Reutlinger y Selowsky (1976). 
A diferencia de los estudios anteriores, en que los grupos de población estuvieron definidos a partir de los niveles de ingreso, región y actividad, en este trabajo se hizo la agrupación en clases sociales, definidas a partir de la inserción del jefe del hogar en el aparato productivo.

En la siguiente sección se hace una estimación, por clase social, de la brecha entre el gasto en alimentos realizado y el requerido. En otra sección se calcula el costo fiscal asociado a las medidas mencionadas, en equilibrio parcial. En la cuarta sección, se estima el costo fiscal y los efectos sobre la balanza de pagos y los niveles de ingreso y su distribución, en equilibrio general. La sección última se dedica a sintetizar las conclusiones principales.

\section{DIFERENCIA ENTRE EL GASTO REALIZADO Y EL RECOMENDADO}

Para calcular el costo fiscal de las transferencias de ingreso y de los subsidios a los precios es necesario tener una estimación del aumento requerido en el consumo de alimentos. Este monto debe -en principio- ser tal que permita cerrar la brecha entre el consumo de nutrientes prevaleciente y el recomendado.

En este sentido, lo ideal sería contar con estimaciones sobre la brecha nutricional para distintos grupos de la población. En México, el Instituto Nacional de la Nutrición ha realizado varias encuestas para estimar dicha brecha. ${ }^{3}$ Sin embargo, estas fuentes de información generalmente no incluyen datos suficientes para relacionar consumo a ingreso en funciones de demanda, por ejemplo. Por otra parte, es prácticamente imposible hacer compatible la información de las encuestas de nutrición con las de ingreso-gasto. Para hacer esto último se tiene que suponer, en primer término, que los grupos de población que captan ambos tipos de encuestas son los mismos.

El cálculo del costo fiscal requiere estimar elasticidades-ingreso y precio; por ello, se optó por estimar los déficit de consumo alimentario con la información que contiene la Encuesta de Ingresos y Gastos de 1977 (Secretaría de Programación y Presupuesto). Es importante tener en cuenta, sin embargo, que esta fuente es menos adecuada que las encuestas sobre nutrición si lo que se desea es tener

3 Véase Instituto Nacional de la Nutrición (1979). Según los resultados de la última encuesta de este organismo (1979), se estima que alrededor de 35 millones de personas padecen algún grado de desnutrición. 
una estimación lo más detallada y precisa de las deficiencias proteínicas y calóricas de distintos grupos de la población. Por esta razón, los cálculos que se emprenden aquí deben verse más desde la óptica metodológica para la comparación entre el análisis de equilibrio parcial y el de equilibrio general, que como una descripción cabal de la situación en materia de nutrición.

El análisis se hará agrupando la población por clases sociales. Hemos distinguido siete clases sociales: campesinos, jornaleros y capitalistas agrícolas, en el sector rural; $y$, asalariados, capitalistas no agrícolas, comerciantes y marginales urbanos, en el sector urbano. ${ }^{4}$ Los criterios seguidos para ubicar a los hogares de la encuesta en las siete clases, aparecen en el Cuadro A.2 del Apéndice.

Los déficit de consumo por clase social se calcularon de la manera siguiente: Con la información de la Encuesta de 1977, se obtuvo el gasto per cápita diario, por clase, en el total de alimentos, en maiz y frijol, en otros productos agropecuarios, y en alimentos procesados. ${ }^{5}$ Esto nos da una estimación del consumo alimentario vigente (columna 1 del Cuadro 1). Por otra parte, el consumo recomendado se calcula a partir de las cantidades que aparecen en la Canasta Básica Recomendable, Sistema Alimentario Mexicano, 1980, habiéndose agrupado los bienes de la misma forma (columna 2 del Cuadro 1). La diferencia entre ambas cifras (columna 3 del Cuadro 1) es el déficit en el gasto.

Este déficit está calculado con precios que incluyen el margen de comercialización (o sea, el consumo del sector comercio). ${ }^{6}$ Sin embargo, para fines de nuestro análisis, es necesario conocer el déficit del consumo en términos "reales" (es decir, excluyéndose el consumo en comercio). Para obtenerlo, se divide el déficit monetario entre

4 El fundamento de esta clasificación de la población viene en Gibson, Lustig y Taylor (1982b:4-6).

5 La clasificación de los alimentos en estos grupos se hizo para calcular el déficit conformable con los sectores productivos del modelo de equilibrio general que se describe en la sección IV.

6 La canasta básica recomendable se transformó de gramos a flujos monetarios usando precios de 1977, provenientes de la Secretaría de Comercio. Para poder hacer la comparación entre los gastos actuales (provenientes de la Encuesta) y los recomendados se los convirtió a precios de 1975 con el índice de precios al consumidor correspondiente a alimentos. Se hace el supuesto de que los precios implícitos en los gastos registrados en la Encuesta son idénticos a los registrados por SECOM. 


\section{Cuadro 1}

Déficit en el gasto en alimentos (per cápita diarios a precios de 1975)

\begin{tabular}{|c|c|c|c|c|}
\hline & $\underset{\text { actual }}{C} \mathrm{C}$ & $\begin{array}{l}m o \\
\text { recomendado }\end{array}$ & $\begin{array}{r}D \dot{e} \\
\text { con margen } \\
(\text { sector } 3)\end{array}$ & $\begin{array}{l}i t \\
\text { sin margen } \\
(\text { sector } 4)\end{array}$ \\
\hline \multicolumn{5}{|c|}{ Maiz y frijol (sector 1) } \\
\hline Marginales urbanos & 0.7673 & 0.8542 & 0.0869 & 0.0756 \\
\hline \multicolumn{5}{|c|}{ Otros productos agropecuarios (sector 2) } \\
\hline $\begin{array}{l}\text { Campesinos } \\
\text { Jornaleros } \\
\text { Marginales urbanos }\end{array}$ & $\begin{array}{l}1.0325 \\
0.9633 \\
1.3486\end{array}$ & $\begin{array}{l}1.8712 \\
1.8712 \\
1.8712\end{array}$ & $\begin{array}{l}0.8387 \\
0.9080 \\
0.5226\end{array}$ & $\begin{array}{l}0.7293 \\
0.7895 \\
0.4544\end{array}$ \\
\hline \multicolumn{5}{|c|}{ Alimentos procesados (sector 5) } \\
\hline $\begin{array}{l}\text { Campesinos } \\
\text { Jornaleros }\end{array}$ & $\begin{array}{ll}3.0 & 057 \\
3.1 & 094\end{array}$ & $\begin{array}{l}3.7349 \\
3.7349\end{array}$ & $\begin{array}{l}0.7292 \\
0.6255\end{array}$ & $\begin{array}{l}0.5833 \\
0.5004\end{array}$ \\
\hline
\end{tabular}

Fuente: Encuesta Nacional de Ingresos y Gastos de los Hogares: 1977 (Secretaría de Programación y Presupuesto).

1 Consumo actual: se calcula con base en la encuesta de Ingresos y Gastos de los Hogares 1977 (SPP) actualizado a precios de 975 con el índice de precios al consumidor de alimentos, bebidas y tabaco.

2 Consumo recomendado: proviene de la canasta Básica Recomendable elaborada por el Sistema Alinentario Mexicano, 1980, y se actualiza de la misma forma que el caso anterior.

3 Déficit con margen: (2) - (1). Incluye el margen de comercialización.

ión 4 Deficit sin margen: es igual al déficit con mirgen, pero entre el precio al consumidor (que incluye los márgenes de comercialización). El margen de comercialización para maiz y trijol, y otros productos agropecuarios se estimó en $.15, y$ para alimentos procesados
se estimó en is (Lustig, 1982a). 
$(1+b)$, donde $b$ es el margen de comercialización. ${ }^{7}$ Estrictamente no se trata del déficit en términos reales (o físicos) porque está a precios de productor; no obstante, como para fines de la comparación se supone que todos los precios son iguales a la unidad (o, mejor dicho son relativos a los precios de mercado vigentes en ese momento), lo hemos denominado déficit real.

Las únicas clases que tuvieron un déficit en el consumo de algunos de los tres grupos de alimentos, son los campesinos y jornaleros $y$, en menor grado, los marginales urbanos. El resto de las clases gasta en alimentos un monto igual o mayor al recomendado. ${ }^{8}$ Los déficit que aparecen en el cuadro 1 son los que se usan para calcular el costo fiscal de la transferencia de ingreso y del subsidio al precio final.

\section{COSTO FISCAL EN EQUILIBRIO PARCIAL}

En esta sección se calcula el costo fiscal asociado a la transferencia de ingreso y al subsidio al precio, en equilibrio parcial. Se contemplan dos tipos de subsidio: el que beneficia únicamente a ciertas clases previamente seleccionadas, y que se llama discriminatorio, y el que beneficia a todos los consumidores del producto subsidiado, denominado generalizado.

Bajo el supuesto de que la oferta puede incrementarse "indefinidamente" a un precio dado (con importaciones, por ejemplo), se puede demostrar (véase el Apéndice) que el costo fiscal (por unidad de incremento en el consumo) de una transferencia de ingresos, es igual a: 9

$$
C F u=1 / \theta
$$

7 La demostración es muy sencilla. Sean $p^{\prime}(i)$ el precio al consumidor, $p(i)$ el precio al productor, $d(i)$ el déficit en términos físicos, y $b^{\prime}$ el margen (monetario) de comercialización, por definición tenemos que:

$$
d(i) * p^{\prime}(i)=d(i) * p(i) *\left(1+b^{\prime}\right)
$$

por lo tanto, $d(i)^{*} p(i)=d(i) * p^{\prime}(i) /\left(1+b^{\prime}\right)$.

8 Cabe hacer la aclaración, sin embargo, de que esto no significa que el resto de la población esté adecuadamente nutrida, para ello sería necesario conocer los niveles de consumo en nutrientes, cálculo que desafortunadamente no se pudo llevar a cabo a partir de la Encuesta de 1977.

9 Las demostraciones son sencillas y pueden verse en el apéndice. 
donde $C F u$ es el costo por unidad de incremento per cápita diario y $\theta$, la propensión marginal al consumo de la clase beneficiada por la transferencia (cuadro A.4) ${ }^{10}$ Una vez obtenido el costo fiscal unitario per cápita diario, se le multiplica por el incremento requerido, por 365 y, por la población correspondiente (Cuadro A.3), para obtener así el costo total anual. ${ }^{11}$

El costo fiscal por unidad de incremento de un subsidio discriminatorio al precio final se calcula como (véase el Apéndice):

$$
C F u=(1+f) 1 / E d
$$

donde $f$, es el porcentaje requerido de incremento en el consumo y $E d$ es la elasticidad precio de la demanda, correspondiente a la clase subsidiada (cuadro A.4). ${ }^{12}$

Por último, el costo fiscal unitario de un subsidio generalizado es igual a (véase el Apéndice):

$$
C f u=\left(1 / E d^{*} \partial\right)^{*}\left[1+(E T d / E d)^{*} f\right]
$$

donde $\partial$ es la proporción consumida por la clase que se desea subsidiar y ETd, es la elasticidad de la demanda para el total de la población (Cuadro A.4).

Al igual que en el caso de las transferencias, para obtener el costo fiscal anual, los $C F u$ correspondientes se multiplican por el incremento requerido, por la población (subsidiada en el caso discriminatorio, y la total en el generalizado), y por 365 (días).

En el Cuadro 1, puede observarse que de las siete clases sociales contempladas, los campesinos, jornaleros y marginales urbanos no

10 Las propensiones marginales al consumo (Cuadro A.4) provienen de la estimación de un sistema lineal de demanda extendido (Lluch, Powell y Williams, 1977), con los datos de la Encuesta de 1977. El procedimiento se describe en Lustig, $1982 b$.

11 El incremento requerido, en principio, debiera ser idéntico al que aparece en la columna 4 del Cuadro 1 ; sin embargo, al hacer los experimentos de equilibrio general, el déficit del consumo que se genera a partir de los datos del modelo es levemente mayor por problemas de redondeo; para los campesinos, es igual a 0.5858 , y para los jornaleros, a 0.4941 (en lugar de 0.5834 y 0.5004 , respectivamente).

12 Como no se dispone de información directa sobre precios en la Encuesta de 1977, la elasticidad-precio por clase y la total (Cuadro A.4) se obtuvo por el método de Frisch y se desprende de la estimación del sistema lineal de demanda extendido (Lluch, Powell y Williams, 1977). 
alcanzan a gastar los niveles recomendados en la Canasta Básica para varios grupos alimentarios. En principio se pensó hacer los cálculos del costo fiscal de una transferencia, de un subsidio discriminatorio y de un subsidio generalizado, para los tres grupos de bienes: maíz y frijol, otros productos agropecuarios, y alimentos procesados. ${ }^{13}$ Sin embargo, al estimar las transferencias de ingreso necesarias para aumentar el consumo de maiz y frijol y de otros productos agropecuarios, se encontró que el monto que se debía transferir era superior al ingreso que perciben estas clases originalmente; esto se debe a que las propensiones marginales al consumo para estos bienes son muy pequeñas, o sea que, para inducir un aumento en el consumo de estos bienes hay que transferir mucho ingreso. ${ }^{14}$ Por lo tanto, con el fin de hacer las comparaciones, se hicieron los cálculos del costo fiscal asociado a incrementar el consumo de alimentos procesados, en el monto requerido. ${ }^{15}$ En el Cuadro 2 aparecen los montos asociados a cada una de estas medidas.

Los resultados de equilibrio parcial indican que el costo fiscal es mucho menor para un subsidio discriminatorio que para una transferencia de ingresos (el costo de esta última es de aproximadamente el doble). Esto coincide con lo que ya se había observado en estudios anteriores (Lustig, 1982b). Sin embargo, el efecto sobre el nivel de vida de una transferencia de ingresos es superior al de los subsidios a los precios. Esto podrá apreciarse en los resultados de equilibrio general. ${ }^{16}$

En el Cuadro 2 resalta el costo descomunal de un subsidio generalizado: más de 10 veces superior al del subsidio discriminatorio. Además, en términos absolutos, se está subsidiando más a los capitalistas

13 Como se verá más adelante, estos tres grupos de bienes corresponden a los sectores 1,2 y 5 , del modelo de equilibrio general.

14 Por esta razón, cuando se desea subsidiar el consumo de alimentos es mejor hacer uso de cupones: el costo fiscal unitario de éstos es igual a la unidad, mientras que, si por ejemplo, la propensión marginal al consumo es igual a .2 , el costo fiscal unitario de una transferencia es igual a 5.

15 Los alimentos procesados incluyen: carnes, leche y derivados, molienda de trigo y sus productos, molienda de nixtamal y productos del maíz, enlatados de todo tipo, azúcar, café y bebidas.

16 El cambio requerido en el precio se calcula como:

$$
d p / p=f * E d
$$

donde $p$ es el precio inicial, $f$, el incremento requerido, y $E d$, la elasticidadprecio de la demanda de la clase subsidiada. 


\section{Cuadro 2}

Costo fiscal total anual (millones de pesos de 1975)

\begin{tabular}{|c|c|c|c|}
\hline & \multirow[b]{2}{*}{ transferencia } & \multicolumn{2}{|c|}{ Subsidio al precio } \\
\hline & & discriminatorio & generalizado \\
\hline Campesinos & 7063.0 & 3525.3 & 3524.9 \\
\hline Jornaleros & 5427.3 & 2725.1 & 2603.8 \\
\hline Capitalistas & & & \\
\hline agrícolas & -- & $-\infty$ & 2087.4 \\
\hline Asalariados & - & $-\infty$ & 20892.6 \\
\hline Capitalistas & & & \\
\hline no agrícolas & -- & -- & 12451.1 \\
\hline Comerciantes & -- & -- & 6629.8 \\
\hline Marginales & & & 57586 \\
\hline & & & 5100.0 \\
\hline Total & 12490.3 & 6250.4 & 66400.4 \\
\hline
\end{tabular}

Nota: La reducción requerida en el precio de los alimentos procesados para poder cerrar la brecha es igual a $20.8 \%$, en el caso de los campesinos, y a $21.6 \%$ en el de los jornaleros. Para hacer el cálculo del subsidio generalizado se tomó el cambio en el precio requerido para cerrar la brecha de consumo correspondiente a los campesinos (o sea, 20.8\%). (16) 
agrícolas, por ejemplo, que a los campesinos y jornaleros. El subsidio anual per cápita resulta en: ${ }^{17}$

$\begin{array}{lr}\text { Campesinos } & 339.17 \\ \text { Jornaleros } & 292.28 \\ \text { Capitalistas agrícolas } & 6977.89 \\ \text { Asalariados } & 817.77 \\ \text { Capitalistas no agrícolas } & 2442.61 \\ \text { Comerciantes } & 2155.88 \\ \text { Marginales urbanos } & 815.34\end{array}$

Estos montos indican, notoriamente, el carácter regresivo de un subsidio generalizado. Este efecto se aminora en la medida en que el subsidio generalizado sea implementado sobre bienes consumidos en mayor proporción por los grupos de bajos ingresos (Mc Carthy, 1978; Taylor, 1980). Por ello es que en el caso de adoptar un subsidio generalizado (porque por razones de implementación, por ejemplo, es el más factible), es de suma importancia subsidiar aquellos bienes que forman parte de la canasta de consumo popular y que no son consumidos (o lo son en muy poca medida) por las familias de altos ingresos. ${ }^{18}$

\section{COSTO FISCAL Y OTROS FFECTOS EN EQUILIBRIO GENERAL}

En la sección previa hemos calculado el costo fiscal de las transferencias y los subsidios al consumo en equilibrio parcial; es decir, sin tomar en cuenta los efectos indirectos de llevar a cabo estas medidas. En esta sección, en cambio, se hace uso de un modelo de equilibrio general de la economía mexicana para estimar los efectos, en particular sobre el déficit del gobierno y el externo. Asimismo, contemplaremos los efectos sobre la distribución y niveles de ingreso y consumo,

17 Los montos están calculados a pesos de 1975; el año corresponde a la base de datos (la matriz de insumo-producto) que se usa en el modelo de equilibrio general.

18 En Lustig (1982b) se hizo un ordenamiento de los bienes según su intensidad en el consumo y se encontró que maíz en grano, azúcar morena, manteca de cerdo, harina de maíz y frijol, son los cinco primeros productos. La intensidad se refiere a la proporción que del total es consumido por los grupos de bajos ingresos. 
asociados a la transferencia de ingreso y al subsidio al precio de los alimentos procesados.

El modelo macroeconómico es de corto plazo y contempla únicamente el lado real del sistema. ${ }^{19}$ Está compuesto de ocho sectores productivos y siete clases sociales. Las clases sociales son: campesinos, jornaleros, capitalistas agrícolas, asalariados, capitalistas no agrícolas, comerciantes y marginales urbanos; y el criterio seguido para definirlas se basa en considerar tanto el acceso a los medios de producción, como el tipo de racionalidad (paramétrica o estratégica) que define su comportamiento (Gibson y colaboradores, 1982b, op. cit.). Los ocho sectores productivos son: 1 . maíz y frijol; 2 . otros productos agropecuarios; 3. petróleo; 4. fertilizantes; 5 . industria alimentaria; 6. otras industrias y construcción; 7. servicios; y, 8 . comercio. El sector cuyo precio al consumidor es sujeto de subsidio es el señalado en quinto lugar (todos los alimentos procesados; véase la nota 15 ).

Los dos sectores agrícolas (maíz y frijol y, otros productos agropecuarios) tienen una oferta dada y el equilibrio ocurre a través de cambios en los precios; por ello reciben el nombre de sectores de "precios flexibles" (PFLEX). En los seis sectores restantes (petróleo, fertilizantes, industria alimentaria, otras industrias y construcción, comercio y servicios), los precios están determinados por un margen sobre los costos primos totales y se denominan sectores de "precios fijos" (PFIJ). La caracterización de los dos tipos de formación de precios que se describieron más arriba implica que, en los dos primeros sectores (PFLEX), el ajuste recae totalmente sobre los precios, mientras que para los seis restantes (PFIJ), recae totalmente sobre las cantidades.

La producción y el empleo en los sectores de precios fijos están determinados por los niveles de demanda. El modelo no incluye mercados para los "factores" de producción y el salario (monetario) se considera como exógeno. El capital (sin incluir la tierra y otrö recursos naturales) se define como un sector de bienes de producción heterogéneos, que se producen internamente o se importan. La inversión está dada exógenamente en términos reales y el ahorro se ajusta a través de la conjugación de mecanismos keynesianos (aumentos en el nivel de actividad), y del tipo propuesto por Kalecki y Kaldor ("ahorro forzoso" ocasionado a través de cambios en la distribución

19 Las características del modelo se describen en Gibson, Lustig y Taylor (1982a y c) y en Lustig (1982b). 
del ingreso). Asimismo, las exportaciones, el gasto público y las importaciones competitivas están dados exógenamente. Las importaciones no competitivas son endógenas y varían con el nivel de producción según los coeficientes calculados a partir de la matriz de insumoproducto de 1975 (Secretaría de Programación y Presupuesto). Los montos de impuestos indirectos y directos recaudados por el gobierno también varían con el nivel de actividad y con la distribución del ingreso, según los coeficientes estimados (Lustig, 1982c: anexo 1). La formulación algebraica del modelo viene en el apéndice.

La información básica del modelo toma como año base 1975 , por ser el año correspondiente a la matriz de insumo producto más reciente en México. Todos los resultados, entonces, se refieren a los valores de 1975 .

En la sección previa se estimaron los costos fiscales directos de la transferencia de ingresos y de los subsidios al precio final de los alimentos procesados. Ahora nos interesa conocer cuáles son los efectos de estas medidas en equilibrio general. En particular, nos interesa conocer el efecto neto sobre el déficit del gobierno y sobre el ahorro externo, cuando se incorporan al cálculo los efectos interactivos.

El análisis del costo fiscal en equilibrio parcial se hizo suponiendo que la oferta de bienes agrícolas es perfectamente elástica y, por lo tanto, la brecha para mantener el precio inicial constante se cierra con importaciones. Hacer este supuesto en el modelo de equilibrio general significa aumentar las importaciones (competitivas) de los sectores 1 y 2 (maíz, frijol y otros productos agropecuarios respectivamente). Esto es porque el sector productor de alimentos procesados (el sector "industria alimentaria" en el modelo) ha sido caracterizado como sector PFIJ; es decir, el precio es igual a los costos primos más un margen de ganancias; y, entre los costos primos están los insumos intermedios que provienen de los sectores agrícolas 1 y 2 , caracterizados aquí como PFLEJ (los precios se ajustan para equilibrar la demanda con la oferta dada). Por lo tanto, para que se cumpla el supuesto de una oferta "infinitamente" elástica (al precio dado inicialmente) del sector subsidiado, la brecha que se genera entre la demanda y la oferta de los sectores 1 y 2 , cuando se introduce la transferencia o un subsidio (o se aumentan los salarios o el precio de garantía), tiene que cerrarse con importaciones competitivas, que en el modelo se toman como dadas exógenamente. Éstas se aumentarán de manera iterativa, hasta que los precios de los sectores 1 y $2(\mathrm{y}$, por lo tanto, del sector 5$)$ sean idénticos a los precios vigentes antes de simular cualquiera de las medidas mencionadas. 
En el Cuadro 3 se describen los escenarios de política económica que se han simulado. El objetivo de cada una de estas estrategias (con excepción del escenario 4, cuyo fin se describe más adelante) es incrementar el consumo de alimentos procesados de los jornaleros y campesinos, para cerrar la brecha que se presenta en el cuadro 1. Los tres primeros experimentos son idénticos a los analizados en equilibrio parcial: una transferencia de ingreso, un subsidio al precio final (discriminatorio), y un subsidio al precio final (generalizado).

En el escenario 4 se aplicó un subsidio uniforme al precio de los alimentos procesados, generalizado a todas las clases, cuyo monto se calculó de tal forma que el déficit del gobierno y el externo fueran iguales a los que resultaron en el escenario 2 (subsidio discriminatorio). El objetivo de este experimento es ilustrar la pérdida de bienestar que significa implementar un subsidio generalizado, cuando se cuenta con ciertos márgenes posibles para el déficit público y el ex terno. ${ }^{20}$

La quinta simulación es una combinación del tipo de medidas recomendadas por el SAM (aumento en los subsidios al precio de fertilizantes y semillas, y al precio de garantía del sector maíz y frijol), junto con un aumento en el salario (nominal) de los jornaleros. Los aumentos en los subsidios a fertilizantes y semillas son los recomendados por el SAM (.30 y .75 a los precios, respectivamente); los incrementos en el precio de garantía y en los salarios fueron calculados de tal forma que tanto los campesinos como los jornaleros cubrieran el déficit en el consumo de alimentos procesados ${ }^{21}$ (véase Cuadro 2).

\section{Transferencia de ingreso y subsidio discriminatorio (escenarios 1 y 2)}

En la sección anterior vimos que, según los resultados de equilibrio parcial, la transferencia de ingresos resultaba doblemente más cara que el subsidio al precio de los alimentos procesados. En el Cuadro 4 podemos observar que la diferencia relativa entre ambas medidas se mantiene en el análisis de equilibrio general; en el caso de las transferencias de ingreso (escenario 1), el ahorro del gobierno

20 Para mantener los déficit iguales a los montos del escenario 2, se fueron simulando distintos grados de subsidio al precio del sector de alimentos procesados en corridas independientes del modelo.

21 Los incrementos necesarios se calcularon de manera iterativa, suponiendo diferentes combinaciones de precio de garantía y salario nominal en corridas independientes, hasta que los niveles de consumo de alimentos procesados de los jornaleros y campesinos alcanzaron los niveles recomendados. 


\section{Cuadro 3}

Descripción de los escenarios de política económica

\begin{tabular}{|c|c|}
\hline Escenario & Descripción \\
\hline \multirow[t]{2}{*}{1} & $\begin{array}{l}\text { Transferencia de ingreso a los campesinos y jor- } \\
\text { naleros para cerrar su déficit en el consumo de } \\
\text { alimentos procesados (transferencia de } 7063.0 \text { y } \\
5427.3 \text {, respectivamente). }\end{array}$ \\
\hline & $\begin{array}{l}\text { Incremento en las importaciones competitivas de } \\
\text { maíz y frijol y otros productos agropecuarios para } \\
\text { mantener los precios iguales a la situación sin poli- } \\
\text { ticas (incremento de } 360.0 \text { y } 3650.0 \text {, respectiva- } \\
\text { mente). }\end{array}$ \\
\hline \multirow[t]{2}{*}{2} & $\begin{array}{l}\text { Subsidio al precio de los alimentos procesados al } \\
\text { que se enfrentan los campesinos y jornaleros para } \\
\text { cerrar su déficit (subsidio de } 25 \% \text { y } 27 \% \text {, respec- } \\
\text { tivamente). }\end{array}$ \\
\hline & $\begin{array}{l}\text { Incremento en las importaciones competitivas de } \\
\text { maiz y frijol y otros productos para mantener los } \\
\text { precios iguales a la situación sin políticas (incre- } \\
\text { mento de } 179 \text { y } 2208.0 \text {, respectivamente). }\end{array}$ \\
\hline \multirow[t]{2}{*}{3} & $\begin{array}{l}\text { Subsidio al precio de los alimentos procesados al } \\
\text { que se enfrentan todas las clases (subsidio genera- } \\
\text { lizado del } 26 \% \text { ). }\end{array}$ \\
\hline & $\begin{array}{l}\text { Incremento en las importaciones competitivas de } \\
\text { maíz y frijol y otros productos agropecuarios para } \\
\text { mantener los precios iguales a la situación sin polí- } \\
\text { ticas (incremento de } 1374 \text { y } 19110.0 \text {, respectiva- } \\
\text { mente). }\end{array}$ \\
\hline \multirow[t]{2}{*}{4} & $\begin{array}{l}\text { Subsidio al precio de los alimentos procesados al } \\
\text { que se enfrentan todas las clases, con déficit públi- } \\
\text { co y externo igual al que se da en el escenario } 2 \\
\text { (subsidio generalizado de } 3.70 \% \text { ). }\end{array}$ \\
\hline & $\begin{array}{l}\text { Incremento en las importaciones competitivas de } \\
\text { maíz y frijol y otros productos agropecuarios para } \\
\text { mantener los precios iguales a la situación sin poli- }\end{array}$ \\
\hline
\end{tabular}


Cuadro 3

Descripción de los escenarios de políticas económicas (continuación)

\begin{tabular}{ll}
\hline Escenario & \multicolumn{1}{c}{ Descripción } \\
\hline & ticas (incremento de 154.4 y 2178.0 , respectiva- \\
mente). & Políticas de precios de garantía y subsidios a la \\
producción de maí y frijol, con incremento en la \\
oferta de este sector, así como también políticas \\
de aumentos a los salarios agricolas para cerrar el \\
déficit de los campesinos y jornaleros en el consumo \\
de alimentos procesados (incremento en el precio \\
de garantía de 45\%, subsidio al precio de la semilla \\
y de los fertilizantes de 75 y $30 \%$, respectivamen- \\
te; incremento en la producción interna de $2 \% ; y$, \\
aumento en el salario agrícola de $18 \%$ ). \\
Incremento en las importaciones competitivas de \\
otros productos agrícolas para mantener los precios \\
iguales a la situación sin politica (incremento de \\
3420.0).
\end{tabular}

\section{Cuadro 4}

Cambios porcentuales en el ahorro en términos reales

\begin{tabular}{cccc}
\hline $\begin{array}{c}\text { Escenario de } \\
\text { politica } \\
\text { económica }\end{array}$ & $\begin{array}{c}\text { Ahorro } \\
\text { privado }\end{array}$ & $\begin{array}{c}\text { Ahorro } \\
\text { externo }\end{array}$ & $\begin{array}{c}\text { Ahorro del } \\
\text { gobierno }\end{array}$ \\
\hline 1 & 2.1249 & 16.6009 & -59.7022 \\
2 & 0.9521 & 9.5206 & -30.6157 \\
3 & 8.5612 & 82.3300 & -269.5759 \\
4 & 0.9521 & 9.5206 & -30.6157 \\
5 & 1.5077 & 14.3002 & -47.1672
\end{tabular}

Nota: Los resultados provienen del modelo de equilibrio general. 


\section{Cuadro 5}

Estructura del ahorro

\begin{tabular}{cccr}
\hline $\begin{array}{c}\text { Escenario de } \\
\text { politica } \\
\text { económica }\end{array}$ & $\begin{array}{c}\text { Ahorro } \\
\text { privado }\end{array}$ & $\begin{array}{c}\text { Ahorro } \\
\text { externo }\end{array}$ & $\begin{array}{c}\text { Ahorro del } \\
\text { gobierno }\end{array}$ \\
\hline Original & 82.3700 & 11.5000 & 6.1300 \\
1 & 84.1159 & 13.4144 & 2.4696 \\
2 & 83.1479 & 12.6000 & 4.2521 \\
3 & 89.4150 & 20.9772 & -10.3922 \\
4 & 84.1159 & 13.4144 & 2.4696 \\
5 & 83.6129 & 13.1490 & 3.2381 \\
\hline
\end{tabular}

Nota: Los resultados provienen del modelo de equilibrio general. 
disminuye en casi $60 \%$, mientras que en el subsidio discriminatorio (escenario 2), en $30 \%$. Es decir, aun cuando las transferencias implican una expansión mayor del producto y el empleo que el subsidio discriminatorio (Cuadro 6, escenarios 1 y 2 ), el aumento en la recaudación de impuestos indirectos que esto significa es tan pequeño en términos relativos que prácticamente no altera la proporción entre ambas medidas.

La mayor expansión de la producción asociada a la transferencia, sin embargo, sí amortigua el impacto del costo fiscal directo en términos absolutos; mientras que en el caso de la transferencia el gasto público aumenta en 12970.25 millones de pesos de 1975 (de los cuales 12480.3 son originados por la medida), el déficit lo hace en 9536.1 millones; en el caso del subsidio discriminatorio, el gasto aumenta en 6446.4 millones, y el déficit en 4891 millones de pesos. Estas comparaciones ilustran las diferencias entre el costo fiscal directo, calculado en equilibrio parcial, y el costo fiscal "neto" (déficit del gobierno), calculado en el modelo de equilibrio general (Cuadro 15).

En cuanto a la composición del ahorro según sus fuentes, los subsidios discriminatorios, y en mayor medida las transferencias, implican una redistribución de la composición del ahorro desde el gobierno hacia el sector externo y el sector privado, por parte iguales (Cuadro 5).

La transferencia de ingreso implica un aumento mayor del déficit externo; éste sube $16.6 \%$ con la transferencia y $9.5 \%$ con el subsidio discriminatorio (escenarios 1 y 2 del Cuadro 4, respectivamente). Al ser la primera relativamente más expansiva, aumentan en mayor proporción las importaciones no competitivas, por un lado, $y$, por el otro, al generarse un aumento mayor en los ingresos de las clases no agrícolas, se produce una mayor demanda para los dos primeros sectores; como el supuesto es que la oferta se incrementa con importaciones, de tal forma que los precios permanezcan constantes, a mayor demanda mayores tendrán que ser las cantidades importadas. ${ }^{22}$

22 Para ilustrar eato haremos uso de un diagrama de equilibrio parcial:
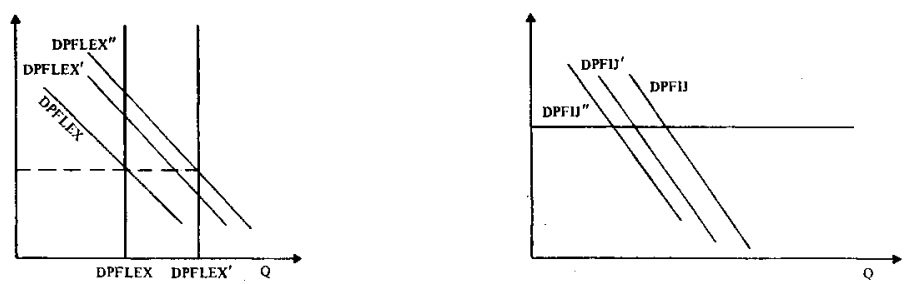
El monto en que aumenta el ingreso real de los campesinos y jornaleros, es superior en el caso de la transferencia que en el subsidio discriminatorio. Esto ocurre porque para inducir el mismo aumento en el consumo de alimentos procesados para cerrar la brecha, dada las elasticidades-precio y las propensiones marginales al consumo, el aumento en el ingreso disponible por medio de transferencias tiene que ser mayor que el generado por una disminución en el precio final ${ }^{23}$ (Cuadros 7, 8 y 9). El aumento en el ingreso real de los campesinos y jornaleros es de más del doble bajo la transferencia $(17.1 \%$ contra $7.7 \%$ ). Esto significa que si se deseara incrementar el ingreso real de estas clases por medio de un subsidio discriminatorio en la misma proporción que con la transferencia, el impacto sobre el déficit público sería más alto (ya que con la transferencia hemos visto que el aumento del déficit es de exactamente el doble).

En el caso de la transferencia, además, hay un efecto mayor en el consumo de todos los productos: compárense las columnas correspondientes a los campesinos y a los jornaleros de los cuadros 8 y 9 . Esto permite disminuir la brecha en el consumo de los otros productos alimentarios; mientras que con la transferencia la brecha en el consumo de otros productos agropecuarios, por ejemplo, disminuye en $20 \%$ y $11 \%$ para campesinos y jornaleros, respectivamente, con el subsidio discriminatorio, la brecha disminuye en sólo $4 \%$ y $2.1 \%$ (Cuadro 14).

La transferencia de ingreso significa, entonces, mayores aumentos en el producto y el empleo, así como en el ingreso y el consumo, tanto de las clases beneficiarias como del resto. En términos del déficit público y del externo, sin embargo, tiene un impacto mucho mayor que el subsidio discriminatorio (Cuadro 4).

Una transferencia de ingreso, un subsidio, etc., a los jornaleros y campesinos implica un desplazamiento de DPFLEX a DPFLEX' y de DPFIJ a DPFI'; este último desplazamiento aumenta los ingresos de los sectores PFIJ y, por lo tanto, hay un segundo desplazamiento a DPFLEX" y DPFU". Para mantener el precio PFLEX en el nivel original es necesario aumentar la oferta a DPFLEX'; la diferencia entre DPFLEX' y DPFLEX son importaciones competitivas. Es evidente que, cuanto mayor sea la expansión de la demanda (DPLEX), más grande será el monto de importaciones.

23 El lector se acordará que, según los cálculos que aparecen en el Cuadro 1, los campesinos y jornaleros mostraron una brecha en el consumo de otros productos agropecuarios, pero que no se trató de eliminar por medio de transferencias porque, dada la propensión marginal al consumo, éstas resultaron ser mayores aún que el ingreso original de estas clases. 


\section{Cuadro 6}

Cambios porcentuales en el producto interno bruto y empleo en los sectores no agrícolas

\begin{tabular}{|c|c|c|c|c|c|c|c|c|}
\hline $\begin{array}{l}\text { liscena- } \\
\text { rios de } \\
\text { pol. econ. }\end{array}$ & Sector & $\begin{array}{l}\text { Petróleo y } \\
\text { energia }\end{array}$ & Fertilizantes & $\begin{array}{l}\text { Industria } \\
\text { alimentaria }\end{array}$ & $\begin{array}{c}\text { Otras } \\
\text { industrias }\end{array}$ & Servicios & Comercio & Total ${ }^{*}$ \\
\hline \multicolumn{9}{|l|}{ PIB } \\
\hline 1 & & 1.8167 & 0.0436 & 3.1885 & 1.7721 & 2.4160 & 2.6470 & 1.9881 \\
\hline 2 & & 0.7572 & 0.0170 & 2.5375 & 0.6782 & 0.9022 & 1.2432 & 0.8940 \\
\hline 3 & & 6.7511 & 0.1488 & 22.8710 & 6.0636 & 8.0647 & 11.1146 & 8.0166 \\
\hline 4 & & 0.8046 & 0.0186 & 2.5590 & 0.7364 & 0.9834 & 1.3080 & 0.9488 \\
\hline 5 & & 1.5690 & 0.3472 & 2.9812 & 1.5487 & 2.1264 & 2.3680 & 1.7966 \\
\hline \multicolumn{9}{|l|}{ Empleo } \\
\hline 1 & & 1.8185 & 0.0436 & 3.1829 & 1.7729 & 2.4160 & 2.6470 & \\
\hline 2 & & 0.7588 & 0.0166 & 2.5256 & 0.6780 & 0.9021 & 1.2432 & \\
\hline 3 & & 6.7530 & 0.1489 & 22.8613 & 6.0647 & 8.0647 & 11.1147 & \\
\hline 4 & & 0.8061 & 0.0180 & 2.5444 & 0.7360 & 0.9832 & 1.3080 & \\
\hline 5 & & 1.5710 & 0.3479 & 2.9898 & 1.5508 & 2.1267 & 2.3681 & \\
\hline
\end{tabular}

Nota: Los resultados provienen del modelo de ęuilibrio general. "Sólo para el caso del producto interno bruto. 


\section{Cuadro 7}

Cambios porcentuales en el ingreso en términos reales

\begin{tabular}{ccccccccc}
\hline $\begin{array}{l}\text { Escenario } \\
\text { de politica } \\
\text { economica }\end{array}$ & $\begin{array}{l}\text { Clase } \\
\text { social }\end{array}$ & Campesinos & Jornaleros & $\begin{array}{c}\text { Capitalistas } \\
\text { agricolas }\end{array}$ & Asalariados & $\begin{array}{c}\text { Capitalistas } \\
\text { no agricolas }\end{array}$ & Comerciantes & $\begin{array}{c}\text { Marginales } \\
\text { urbanos }\end{array}$ \\
\hline 1 & 17.0989 & 17.3404 & 0.0 & 2.0094 & 2.2986 & 2.6521 & 2.3994 \\
2 & 7.6816 & 7.9303 & 0.0 & 0.8688 & 1.0372 & 1.2537 & 1.0956 \\
3 & 7.5129 & 7.6055 & 5.7282 & 14.0388 & 14.8408 & 17.7188 & 19.0749 \\
4 & 0.9543 & 1.0176 & 0.6406 & 1.7204 & 1.8146 & 2.1247 & 2.2912 \\
5 & 17.7771 & 18.2513 & 5.2846 & 1.7669 & 2.0381 & 2.3600 & 2.1196 \\
\hline
\end{tabular}

Nota: Los resultados provienen del modelo de equilibrio general. 


\section{Cuadro 8}

Cambios porcentuales en el consumo en términos reales, escenario de política económica 1

\begin{tabular}{lccccccc}
\hline $\begin{array}{l}\text { Clase } \\
\text { Social }\end{array}$ & Campesinos & Jornaleros & $\begin{array}{c}\text { Capitalistas } \\
\text { agricolas }\end{array}$ & $\begin{array}{c}\text { Asalariados } \\
\text { urbanos }\end{array}$ & $\begin{array}{c}\text { Capitalistas } \\
\text { no agricolas }\end{array}$ & Comerciantes & $\begin{array}{c}\text { Marginales } \\
\text { urbanos }\end{array}$ \\
\hline Maíz y frijol & 3.1595 & 2.9514 & 0.0000 & 0.2254 & 0.0000 & 0.0000 & 0.3356 \\
$\begin{array}{l}\text { Otros prod. } \\
\text { agropecuarios }\end{array}$ & 13.4584 & 12.5679 & 0.0000 & 1.1824 & 0.9655 & 1.0769 & 1.8425 \\
Petróleo & 18.9918 & 17.7212 & 0.0000 & 1.6065 & 1.8310 & 2.0450 & 2.5988 \\
Fertilizantes & 0.0000 & 0.0000 & 0.0000 & 0.0000 & 0.0000 & 0.0000 & 0.0000 \\
Alimentos & 17.8877 & 19.0693 & 0.0000 & 1.5923 & 1.5377 & 1.5377 & 2.3822 \\
procesados & 20.5705 & 17.5857 & 0.0000 & 2.8520 & 3.6568 & 3.6568 & 2.7883 \\
Otras industrias & 20.5733 & 19.2128 & 0.0000 & 1.9628 & 2.2875 & 2.2875 & 2.5954 \\
Servicios & 17.9034 & 17.8732 & 0.0000 & 2.0075 & 2.3067 & 2.3067 & 2.4370 \\
Coniercio & & & & & & & \\
\hline
\end{tabular}

Nota: Los resultados provienen del modelo de equilibrio general. 
Los efectos sobre la distribución del ingreso en ambos casos son favorables para los campesinos y jornaleros, y van en detrimento del resto de las clases. Los cambios son, no obstante, muy pequeños (Cuadro 13).

\section{Subsidio generalizado (escenario 3)}

El subsidio generalizado ${ }^{24}$ tiene un efecto enorme sobre el déficit público y el externo; este último casi se duplica, y aquél sube más de dos y media veces (cuadro 4). Es decir, es económicamente imposible tratar de subsanar la deficiencia alimentaria de ciertas clases con un subsidio generalizado, si bien éste ocasiona una mayor expansión en el producto y en el empleo (Cuadro 6).

Por otra parte, tal como se había indicado, es una medida con tendencias regresivas; la distribución del ingreso se modifica (muy ligeramente) hacia los comerciantes, los capitalistas no agrícolas y los marginales urbanos (estos últimos porque su ingreso se genera parcialmente como una proporción fija de las ganancias; y en contra de campesinos, jornaleros, asalariados y capitalistas agrícolas).

El ingreso real de todas las clases aumenta (Cuadro 7). Las clases más pobres del sector rural (campesinos y jornaleros) tienen incrementos muy similares a los que obtienen con el subsidio discriminatorio, al mismo tiempo que los capitalistas no agrícolas, los comerciantes y los asalariados, tienen aumentos de un porcentaje alrededor de quince veces mayor. Tal vez el único resultado atractivo del subsidio generalizado es que el ingreso de los marginales urbanos sube considerablemente.

Subsidio generalizado con déficit iguales al escenario 2 (escenario 4)

Este experimento fue diseñado para ilustrar la magnitud del beneficio potencial perdido si se aplica un subsidio generalizado, cuando se podría aplicar uno discriminatorio con el mismo costo en términos de los déficit público y externo.

24 Aquí se aplica un subsidio al precio final de los alimentos procesados de la misma magnitud que el que se otorga a los campesinos en el subsidio discriminatorio, pero para todas las clases. Dicho subsidio equivale a una disminución del $20.8 \%$ en el precio inicial. 


\section{Cuadro 9}

Cambios porcentuales en el consumo en términos reales, escenario de políticas económica 2

\begin{tabular}{lccccccc}
\hline $\begin{array}{l}\text { Clase } \\
\text { Social }\end{array}$ & Campesinos & sornaleros & $\begin{array}{c}\text { Capitalistas } \\
\text { agricolas }\end{array}$ & $\begin{array}{c}\text { Asalariados } \\
\text { urbanos }\end{array}$ & $\begin{array}{c}\text { Capitalistas } \\
\text { no agricolas }\end{array}$ & $\begin{array}{c}\text { Comerciantes } \\
\text { urbanos }\end{array}$ \\
Maíz y frijol & 0.6061 & 0.5468 & 0.0000 & 0.0838 & 0.0000 & 0.0000 & 0.1393 \\
$\begin{array}{l}\text { Otros prod. } \\
\text { agropecuarios }\end{array}$ & 2.6746 & 2.4107 & 0.0000 & 0.5315 & 0.4554 & 0.5281 & 0.8580 \\
Petróleo & 3.7478 & 3.3650 & 0.0000 & 0.6958 & 0.8295 & 0.9706 & 1.1886 \\
Fertilizantes & 0.0000 & 0.0000 & 0.0000 & 0.0000 & 0.0000 & 0.0000 & 0.0000 \\
$\begin{array}{l}\text { Alimentos } \\
\text { procesados }\end{array}$ & 18.2359 & 19.8359 & 0.0000 & 0.6999 & 0.7079 & 0.9355 & 1.0960 \\
Otras industrias & 4.0578 & 3.3486 & 0.0000 & 1.2342 & 16.553 & 2.1410 & 1.2728 \\
Servicios & 4.0596 & 3.6590 & 0.0000 & 0.8498 & 1.0356 & 1.2106 & 1.1851 \\
Comercio & 8.7400 & 8.8129 & 0.0000 & 0.8724 & 1.0475 & 1.3130 & 1.1166 \\
\hline
\end{tabular}

Nota:- Los resultados provienen del modelo de equilibrio general. 
En el Cuadro 7 puede observarse que los aumentos en el ingreso real de los campesinos y los jornaleros apenas son del $1 \%$ aproximadamente, mientras que en el escenario 2 (subsidio discriminatorio con los mismos montos en los déficit) eran cercanos al $8 \%$. Esto, desde luego, se refleja en los cambios en el consumo real (Cuadro 11). Al ser éstos tan pequeños, la brecha en el consumo de alimentos procesados de los campesinos se cubre sólo en $11.58 \%$ y la de los jornaleros en $11.44 \%$, cuando en todos los otros casos esta brecha se cubre al $100 \%$ (Cuadro 14).

\section{Aumentos en la retribución al producto y al trabajo (escenario 5)}

En el escenario 5 se aumenta el precio de garantía para el sector maíz y frijol, el subsidio al precio de fertilizantes y semilla mejorada, y el salario que reciben los jornaleros. La magnitud de los aumentos del precio de garantía y del salario se calculó de tal forma que éstos generen un ingreso suficiente para cubrir la brecha en el consumo de alimentos procesados de los campesinos y los jornaleros. Las cifras resultantes son de $43 \%$ de aumento en el precio de garantía, y de $18 \%$ en el salario (nominal). El subsidio al precio de las semillas y fertilizantes es de $.75 \mathrm{y}$ en éste se hace el supuesto de que la oferta de los sectores PFLEX se expande hasta que los precios sean iguales a los iniciales. La diferencia reside en que en este caso la oferta crece parcialmente con producción interna, con respuesta al aumento en la rentabilidad que representa el nuevo precio de garantía y el subsidio a los insumos; en todos los casos anteriores se hizo el supuesto de que la oferta aumenta con importaciones competitivas (véase Cuadro 3 ).

Los efectos sobre el ingreso y consumo reales de los campesinos y jornaleros, son ligeramente superiores a los que acompañan a la transferencia de ingreso (véanse Cuadros 7 y 12 , respectivamente). La distribución del ingreso se mueve de manera más marcada hacia estas dos clases y los que más pierden participación relativa son los capitalistas agrícolas (Cuadro 13). De hecho, éstos son los únicos que pierden ingreso en términos reales (Cuadro 7), como consecuencia de que la ganancia disminuye al aumentarse el salario que pagan a sus empleados (jornaleros). Esta disminución ocurre a pesar de que también son beneficiarios del aumento en el precio de garantía.

La disminución en el ahorro del gobierno es de $47.2 \%$ mientras que con la transferencia lo es de $59.7 \%$. Por otra parte, el ahorro externo sube en $14.3 \%$ contra $16.6 \%$ en el caso de la transferencia 


\section{Cuadro 10}

Cambios porcentuales en el consumo en términos reales, escenario de política econónica 3

\begin{tabular}{lccccccc}
\hline $\begin{array}{l}\text { Clase } \\
\text { Social }\end{array}$ & Campesinos & Jornaleros & $\begin{array}{c}\text { Capitalistas } \\
\text { agricolas }\end{array}$ & $\begin{array}{c}\text { Asalariados } \\
\text { urbanos }\end{array}$ & $\begin{array}{c}\text { Capitalistas } \\
\text { no agricolas }\end{array}$ & Comerciantes & $\begin{array}{c}\text { Marginales } \\
\text { urbanos }\end{array}$ \\
\hline Maíz y frijol & 0.6420 & 0.5661 & 0.0000 & 1.1772 & 0.0000 & 0.0000 & 2.0102 \\
$\begin{array}{l}\text { Otros prod. } \\
\text { agropecuarios }\end{array}$ & 2.5206 & 2.2805 & 0.7930 & 5.8010 & 4.5777 & 5.1142 & 10.5335 \\
Petróleo & 3.5625 & 3.2107 & 1.5147 & 7.9159 & 8.7260 & 9.7494 & 14.8783 \\
Fertilizantes & 0.0000 & 0.0000 & 0.0000 & 0.0000 & 0.0000 & 0.0000 & 0.0000 \\
Alimentos & 18.0092 & 18.8624 & 18.2945 & 26.1280 & 27.0678 & 31.2288 & 30.4024 \\
procesados & 3.8561 & 3.1948 & 3.1903 & 14.0680 & 17.4457 & 21.5609 & 15.9886 \\
Otras industrias & 3.8587 & 3.4918 & 1.8905 & 9.6742 & 10.9062 & 12.1838 & 14.8753 \\
Servicios & 8.5485 & 8.3884 & 6.2190 & 14.5058 & 15.3945 & 18.3215 & 20.2115 \\
Comercio & & & & & & & \\
\hline
\end{tabular}

Nota: Los resultados provienen del modelo de equilibrio general. 


\section{Cuadro 11}

Cambios porcentuales en el consumo en términos reales, escenario de política ecunómica 4

\begin{tabular}{lccccccc}
\hline $\begin{array}{c}\text { Sector } \\
\text { social }\end{array}$ & Campesinos & Jornaleros & $\begin{array}{c}\text { Capitalistas } \\
\text { agricolas }\end{array}$ & $\begin{array}{c}\text { Asalariados } \\
\text { urbanos }\end{array}$ & $\begin{array}{c}\text { Capitalistas } \\
\text { no agricolas }\end{array}$ & $\begin{array}{c}\text { Comerciantes } \\
\text { Marginales } \\
\text { urbanos }\end{array}$ \\
\hline Maíz y frijol & 0.0626 & 0.0648 & 0.0000 & 0.1299 & 0.0000 & 0.0000 & 0.2335 \\
$\begin{array}{l}\text { Otros prod. } \\
\text { agropecuarios }\end{array}$ & 0.3510 & 0.3496 & 0.0838 & 0.7518 & 0.5834 & 0.6428 & 1.3466 \\
$\begin{array}{l}\text { Petróleo } \\
\text { Fertilizantes }\end{array}$ & 0.4640 & 0.4523 & 0.1114 & 0.9902 & 1.0656 & 1.1818 & 1.8727 \\
$\begin{array}{l}\text { Alimentos } \\
\text { procesados }\end{array}$ & 0.0000 & 0.0000 & 0.0000 & 0.0000 & 0.0000 & 0.0000 & 0.0000 \\
Otras industrias & 0.0622 & 2.2101 & 2.0564 & 2.9106 & 3.0083 & 3.4430 & 3.3093 \\
Servicios & 0.5007 & 0.4601 & 0.2294 & 1.7578 & 21.2810 & 2.6088 & 2.0085 \\
Comercio & 0.5022 & 0.5033 & 0.1368 & 1.2097 & 1.3309 & 1.4746 & 1.8694 \\
\hline
\end{tabular}

Nota: Los resultados provienen del modelo de equilibrio general. 


\section{Cuadro 12}

Cambios porcentuales en el consumo en términos reales, escenario de política económica 5

\begin{tabular}{lccccccc}
\hline $\begin{array}{c}\text { Clase } \\
\text { social }\end{array}$ & Campesinos & Jornaleros & $\begin{array}{c}\text { Capitalistas } \\
\text { agricolas }\end{array}$ & $\begin{array}{c}\text { Asalariados } \\
\text { urbanos }\end{array}$ & $\begin{array}{c}\text { Capitalistas } \\
\text { no agricolas }\end{array}$ & Comerciantes & $\begin{array}{c}\text { Marginales } \\
\text { urianos }\end{array}$ \\
\hline Maíz y frijol & 3.2767 & 3.0989 & 0.0000 & 0.1896 & 0.0000 & 0.0000 & 0.2894 \\
$\begin{array}{l}\text { Otros prod. } \\
\text { agropecuarios }\end{array}$ & 13.9765 & 13.2129 & -2.3181 & 1.0186 & 0.8357 & 0.9390 & 1.6124 \\
Petróleo & 19.7653 & 18.6707 & -4.3814 & 1.4188 & 1.6299 & 1.8270 & 2.3057 \\
Fertilizantes & 0.0000 & 0.0000 & 0.0000 & 0.0000 & 0.0000 & 0.0000 & 0.0000 \\
Alimentos & 18.5952 & 20.0680 & -3.4105 & 1.3881 & 1.3489 & 1.7170 & 2.0982 \\
procesados & 21.4071 & 18.5262 & -9.2657 & 2.5165 & 3.2518 & 4.0313 & 2.4722 \\
Otras industrias & 21.4111 & 20.2414 & -5.4793 & 1.7333 & 2.0358 & 2.2808 & 2.3022 \\
Servicios & 18.6220 & 18.8266 & -5.4712 & 1.7667 & 2.0472 & 2.4195 & 2.1544 \\
Comercio & & & & & & & \\
\hline
\end{tabular}

Wota: Los resultados provienen del modelo de equilibrio general 
(Cuadro 4). Claramente, en la medida en que el costo de la redistribución del ingreso sea absorbido por otras clases del sector privado las presiones sobre el déficit público y el externo son menores. Sin embargo, esto puede traer consecuencias negativas sobre la inversión y la producción. Una manera de evitar esto sería mediante una redistribución, por la vía fiscal, de la carga. En el ejemplo que estamos analizando, la disminución en el ingreso de los capitalistas agrícolas es de un monto similar al aumento del ingreso de los capitalistas no agrícolas y de los comerciantes, si se hiciese una transferencia de los segundos a los primeros, se podría llegar a una situación en que el ingreso real de las clases con mayores ingresos permaneciera constante, mientras se obtuviera un incremento muy considerable para campesinos y jornaleros (alrededor del $18 \%$ ) y uno pequeño para los asalariados y marginales urbanos (alrededor del $2 \%$ ).

\section{CONCLUSIONES}

De la comparación entre la transferencia de ingreso, el subsidio discriminatorio y el subsidio generalizado, en equilibrio parcial, se encontraron los resultados siguientes: el costo fiscal del subsidio discriminatorio es dos veces más bajo que el de la transferencia, y 10 veces menor que el subsidio generalizado. Este último, por otra parte, tiene claras tendencias regresivas.

Este ordenamiento de las medidas en función de la carga fiscal, se sostiene en el análisis de equilibrio general. Sin embargo, al incorporar en el cálculo los efectos expansivos sobre la producción de cualquiera de las tres medidas, se encuentra que éstos amortiguan levemente el impacto del costo fiscal directo en términos absolutos.

En términos de otros criterios la transferencia de ingreso, en. comparación con el subsidio discriminatorio, significa mayores aumentos en el producto y el empleo, así como en el ingreso y el consumo, tanto de las clases beneficiarias, como del resto. La presión sobre la balanza de pagos es, no obstante, sustantivamente mayor en el caso de la transferencia.

Tanto en el caso de las transferencias como del subsidio discriminatorio, los efectos sobre la distribución del ingreso son ligeramente favorables para los campesinos y jornaleros, y van en detrimento del resto de las clases.

Por la magnitud de los efectos del subsidio generalizado sobre el déficit público y el externo, parece económicamente imposible tratar 


\section{Cuadro 13}

Distribución del ingreso real

\begin{tabular}{lcccccccc}
\hline $\begin{array}{l}\text { Escenario } \\
\text { politica } \\
\text { econimica }\end{array}$ & $\begin{array}{c}\text { Clase } \\
\text { social }\end{array}$ & Campesiros & Jornaleros & $\begin{array}{c}\text { Capitalistas } \\
\text { agricolas }\end{array}$ & $\begin{array}{c}\text { Asalariados } \\
\text { urbanos }\end{array}$ & $\begin{array}{c}\text { Capitalistas } \\
\text { no agricolas }\end{array}$ & Comerciantes & $\begin{array}{c}\text { Marginales } \\
\text { urbanos }\end{array}$ \\
\hline Original & 4.0556 & 3.0769 & 4.9079 & 37.4120 & 30.7375 & 14.1757 & 5.6445 \\
1 & 4.5907 & 3.4987 & 4.7539 & 36.9830 & 30.4712 & 14.1014 & 5.6011 \\
2 & 4.2952 & 3.2743 & 4.8332 & 37.2036 & 30.6177 & 14.1505 & 5.6255 \\
3 & 3.8066 & 2.8977 & 4.5414 & 37.3393 & 30.9280 & 14.6047 & 5.8823 \\
4 & 4.0146 & 3.0553 & 4.8551 & 37.4073 & 30.7621 & 14.2302 & 5.6754 \\
5 & 4.6366 & 3.5406 & 4.5235 & 37.0493 & 30.5207 & 14.1201 & 5.6091 \\
\hline
\end{tabular}

Nota: Los resultados provienen del modelo de equilibrio general. 
de subsanar la deficiencia alimentaria de ciertas clases con un subsidio generalizado, además de que así se manifiestan tendencias regresivas en términos distributivos.

Por otra parte, si se implementa un subsidio generalizado, manteniendo la presión sobre el déficit público y externo del subsidio discriminatorio, las clases con mayores problemas de nutrición (campesinos y jornaleros) apenas obtienen una mejora.

Cuando se intenta mejorar la situación de estas clases mediante aumentos en la retribución a lo que producen y a la fuerza de trabajo, transfiriendo parte del costo a otras clases del sector privado, las presiones sobre el déficit público y el externo son menores. Las consecuencias negativas que esto puede traer sobre la inversión y la producción se pueden aminorar mediante una redistribución equitativa de la carga entre los sectores de altos ingresos, por la vía fiscal, por ejemplo.

En síntesis, si se trata de minimizar el costo fiscal y el efecto en la balanza de pagos, para generar una mejora en las condiciones de nutrición de ciertos sectores de la población, de las medidas analizadas la más atinada es el subsidio discriminatorio. En otras palabras, si el gobierno dispone de un monto preestablecido para combatir la desnutrición, le conviene encontrar la forma de vender ciertos productos alimentarios básicos a un precio más bajo, exclusivamente a las clases que desea beneficiar. Una forma de hacerlo es subsidiando los productos de consumo primordialmente popular y venderlos en tiendas ubicadas en las zonas habitadas por la población de bajos ingresos.

Sin embargo, desde el punto de vista fiscal estrictamente, resultan más eficaces los cupones de alimentos (Lustig, 1982a). Por lo tanto, la decisión entre el subsidio discriminatorio y los cupones debe contemplar los costos administrativos y las posibilidades de aplicación. Es posible que para algunos productos y algunos grupos de población resulte más adecuado uno que otro.

Por otra parte, es importante recalcar que los efectos inflacionarios de este tipo de medidas se han eliminado al suponer que los cuellos de botella se suprimen con importaciones. En otro trabajo, se ha visto que, cuando esto no ocurre, un subsidio al precio puede llevar a una disminución en el consumo real (Gibson, Lustig y Taylor, 1982a).

Es importante observar también que las presiones sobre las finanzas públicas, generadas a partir de cualquier intento de mejorar las condiciones de vida de ciertos sectores de la población, serán mayo- 
Cuadro 14

Proporción satisfecha de los déficit alimentarios

\begin{tabular}{crrrrrrr}
\hline Eiscenario & \multicolumn{2}{c}{ Campesinos } & \multicolumn{2}{c}{ Jornales } & \multicolumn{2}{c}{ Marginales urbanos } \\
\hline & OA & AP & OA & AP & MF & OA \\
1 & 19.97 & 100 & 10.98 & 100 & 3.53 & 7.42 \\
2 & 3.97 & 100 & 2.10 & 100 & 1.46 & 3.45 \\
3 & 3.74 & 100 & 1.99 & 100 & 21.44 & 42.41 \\
4 & 0.52 & 11.58 & 0.30 & 11.44 & 2.52 & 5.43 \\
5 & 20.74 & 100 & 11.55 & 100 & 3.05 & 6.49 \\
\hline
\end{tabular}

$O A=$ Otros productos agropecuarios

$M F=$ Maiz y frijol

$\mathbf{A P}=$ Alimentos procesados

Nota L Los déficit vienen en el cuadro 1, y la descripción de las políticas en el cuadro 3 . 


\section{Cuadro 15}

Incrementos en el gasto y el déficit público

(millones de pesos de 1975)

\begin{tabular}{cccc}
\hline Escenario & Costo fiscal & Gasto & Déficit \\
\hline 1 & 12490.3 & 12970.2 & 9536.1 \\
2 & 6250.4 & 6446.4 & 4891.0 \\
3 & 66262.0 & 68422.1 & 48053.9 \\
4 & 6250.4 & 6446.4 & 4891.0 \\
5 & 10087.6 & 10540.8 & 7533.1 \\
\hline
\end{tabular}

luente: Cálculos con base en el modelo de equilibrio general.

Nota: Los incrementos se calculan con respecto a los valores originales registrados para 1975 , los montos verdaderos del escenario 4 son ligeramente diferentes por errores de redondeo: $6414.7,6624.0$ y 4985.3 , respectivamente.

res en la medida en que simultáneamente se traten de proteger los ingresos de las clases más pudientes. Esto es evidente cuando se compara la carga de una transferencia con la asociada al escenario en donde se aumenta la retribución al producto y al trabajo. Gran parte de la llamada "ineficiencia" del sector público es resultado de los malabarismos que se hacen para cumplir con todos. 
Apéndice

DERIVACIÓN DE LAS FóRMULAS DE COSTO FISCAL

\section{Transferencia de ingreso}

Supongamos que se requiere incrementar el consumo en alimentos de cierta clase en $d c(r)$ unidades (la $r$ se refiere a requerido). Para determinar el monto de ingreso que se tiene que transferir $[d y(r)]$ se necesita conocer qué parte del ingreso adicional dedica esta clase al consumo de los alimentos; este dato es simplemente la propensión marginal al consumo $(m=d c / d y$, por definición).

De aquí es obvio que:

(1) Costo fiscal $=d y(r)=p / m^{*} d c(r)$

donde $p$ es el precio por unidad.

Por lo tanto, el costo fiscal por unidad incrementada (per cápita diario) será:

(2) $C F u=p / m$ 
$y$, el costo fiscal anual total:

(3) $D F t=D F u * d c(r) * N * 365$

donde $N$ es la población beneficiada.

Subsidio al precio final (discriminatorio)

El costo fiscal (per cápita diario) de un subsidio discriminatorio es igual a:

(4) Costo fiscal $=\left(p-p^{\prime}\right) *[c+d c(r)]=$ $=d p(r)[c+d c(r)]$

donde $p$ 'es el precio subsidiado.

Para conocer $d p(r)$, o sea, en cuánto tiene que cambiar el precio para inducir un incremento en el consumo igual a $d c(r)$, se necesita conocer la elasticidad-precio de la demanda $[E d=(d c / c) /(d p / p)]$,

(5) $d p(r)=(1 / E d)^{*}[d c(r) / c]^{*} p$

Sustituyendo (5) en (4), tenemos que

(6) Costo fiscal $=(1 / E d)^{*} d c(r)^{*} p^{*}[1+f]$

donde $f$ es igual al incremento requerido en porcentajes. El costo fiscal por unidad de incremento es igual a:

(7) $C F u=(1 / E d) * p^{*}[1+f]$

y el costo fiscal total:

(8) $C F t=D F u * d c(r) * N * 365$

\section{Subsidio al precio final (generalizado)}

En este caso toda la población tiene acceso al bien subsidiado. Por lo tanto, 
(9) Costo fiscal $=d p(r)^{*}[c(t)+d c(t)]=$ $=d p(r)^{*}[c(t)+d c(r)+d c(n r)]$

donde $c(t)$ es el consumo de toda la población existente antes del subsidio; $d c(t)$ es el aumento total del consumo después del subsidio; y, $d c(n r)$ es la parte de $d c(t)$ que no se requería incrementar (es decir, el aumento en el consumo de las clases a las que no se intenta subsidiar).

Como antes, al organismo que implementa el subsidio le interesa incrementar el consumo de cierta clase en un monto requerido [que hemos llamado $d c(r)]$; por ello, $d p(r)$ es igual al del subsidio discriminatorio.

Por otra parte,

$$
\text { (10) } d c(t)=d p(r)^{*} E T d^{*} c(t)^{*} p
$$

donde $E T d$ es la elasticidad-precio de la demanda de toda la población.

Si sustituimos la expresión de $d p(r)(5)$ en (9) y en (10), y la (10) en (9) tenemos que:

$$
\text { (11) } \text { Costo fiscal }=(1 / E d)^{*} p^{*} f^{*} c(t)^{*}\left[1+(E d / E T d)^{*} f\right]
$$

El costo fiscal por unidad de incremento es entonces igual a:

$$
\text { (12) } C F u=(1 / E d) *(1 / \partial)^{*} p *[1+(E d / E T d) * f]
$$

donde $\partial$ es la proporción del bien consumida por la clase subsidiada; $y$ el costo fiscal total anual:

$$
\text { (13) } C F=C F u^{*}[d c(r)+d c(n r)]^{*} N^{\prime} 365
$$

Donde $N$ 'es la población total.

En el Cuadro A.1 se presentan las fórmulas de los costos fiscales de manera resumida. Como en todas aparece el mismo $p$, para fines de la comparación dividimos a las fórmulas (2), (7) y (12) por $p$.

La transferencia de ingreso será más cara cuanto menor sea la propensión marginal al consumo. El costo del subsidio al precio discriminatorio está inversamente relacionado con la magnitud de la elasticidad-precio y directamente con el porcentaje de incremento. Por último, el subsidio generalizado tendrá un costo mayor cuanto más grande sean la elasticidad-precio total y el incremento porcen- 
tual requerido, y cuanto más baja sean la proporción consumida y la elasticidad-precio de la clase subsidiada. Una presentación detallada sobre las propiedades, ventajas y desventajas de las distintas medidas, y de cómo afecta el costo fiscal cuando se rompe el supuesto de un precio de oferta constante, puede verse en Reutlinger y Selowsky (op. cit.).

\section{ECUACIONES DEL MODELO}

\section{Variables}

$p$ precio

$x$ producción

$r$ margen de ganancia

$p$, precio al consumidor

$E$ gasto total

$Y$ ingreso

$c$ consumo

$S G$ ahorro del gobierno

$S F$ ahorro externo

$S P$ ahorro privado

\section{Parámetros}

$t \quad$ tasa de impuestos indirectos

a coeficientes de insumo producto

$w$ salario nominal

$l$ coeficientes de empleo

$I$ inversión

$d s$ cambio en inventarios

$g$ gasto corriente del gob.

$z$ exportaciones

$m$ importaciones competitivas

$O$ consumo de subsistencia

$M$ propensión marginal al cons.

$p^{*}$ precio de garantía

\section{Parámetros}

$s \quad$ propensión al ahorro

$u$ proporción del valor agregado que va a los campesinos

$v \quad$ proporción del valor agregado que va a los marginales urbanos

pi precio internacional de las importaciones

$q$ tasa de impuestos directos

$b$ márgenes de comercialización

$e \quad$ tipo de cambio

wg salarios del gobierno

$m c$ importaciones de consumo

$m i$ importaciones de inversión

$m g$ importaciones del gobierno

$T R$ transferencias de ingreso

$S U B$ subsidio al precio final 
LUSTIG: ANÁLISIS DE POLÍtICAS DE CONSUMO ALIMENTARIO 219

\section{ECUACIONES}

\section{Precios}

$P_{j}=\left(1+t_{j}\right)\left(1+r_{j}\right)\left(\Sigma p_{i} a_{i j}+w_{j} 1\right)$

$j=3, \ldots, 8$ (sectores) $i=1, \ldots, 9$ (idem.)

Balances de oferta y demanda

$x_{i}=\sum_{j} a_{i j} x_{j}+c_{i}+I_{i}+d s_{i}+g_{i}+z_{i}-m_{i}$

$i, j=1,2, \ldots, 8$ (sectores)

\section{Funciones de consumo}

$c_{i j}=\left[\theta_{i j}+M_{i j} / P_{i j}\left(E_{i}-\sum_{j} P_{i j} \theta_{i j}\right)\right] \begin{aligned} & i=\mathrm{I}, \ldots, \mathrm{VII} \text { (clases) } \\ & j=1, \ldots, 7 \text { (sectores) }\end{aligned}$

\section{Gasto total por clase}

$E_{i}=\left(1-s_{i}\right)\left(1-q_{i}\right) Y_{i} i=\mathrm{I}, \ldots, \mathrm{VII}$ (clases)

Ingreso total por clase

$$
\begin{aligned}
& Y_{\mathrm{I}}=\sum_{i=1}^{2}\left(P_{i}-\sum_{j} P_{j} a_{j i}\right) x_{i} u_{i}+T R_{\mathrm{I}} \begin{array}{r}
\text { (campesinos; } p=p^{*} \text { reci- } \\
\text { ben el precio de garantía) }
\end{array} \\
& Y_{\mathrm{II}}=\sum_{i=1}^{2} w 1_{i} x_{i}+T R_{\mathrm{II}} \quad \text { (jornaleros) } \\
& Y_{I I I}=\sum_{i=1}^{2}\left[\left(1-u_{i}\right)\left(P_{i}-\underset{j}{\sum} P_{j} a_{j i}\right)-w 1_{i}\right] \text { (capitalistas agrícolas) } \\
& Y_{\mathrm{IV}}=\sum_{i=3}^{8} w 1_{i} x_{i}\left(1-v_{\mathrm{IV}}\right) \text { (asalariados) }
\end{aligned}
$$




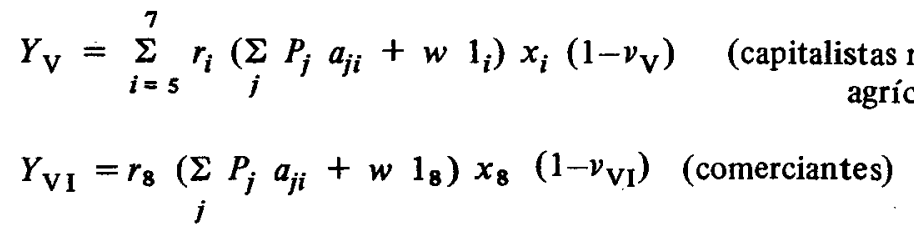

$$
\begin{aligned}
& Y_{\mathrm{VII}}=\sum_{j}\left[v_{j}\left[v_{j} /\left(1-v_{j}\right)\right]\right] y_{i}+T R_{\mathrm{VII}} j=\mathrm{IV}, \mathrm{V}, \mathrm{VI} \quad \begin{array}{l}
\text { (marg. } \\
\text { urbanos) }
\end{array}
\end{aligned}
$$

Precios al consumidor

$$
P_{i j}=P_{i}+b_{i j}+S U B_{j} \quad \begin{aligned}
& i=1,2, \ldots, 7 \text { (sectores) } \\
& j=\mathrm{I}, \ldots, \mathrm{VII} \text { (clases) }
\end{aligned}
$$

Consumo de comercio (sector 8)

$$
\begin{array}{cl}
c_{i}=\underset{i}{\Sigma} \sum_{j} c_{i j} b_{i j} & i=1,2, \ldots, 7 \text { (sectores) } \\
j=1, \ldots, \text { VII (clases) }
\end{array}
$$

\section{Ahorro del gobierno}

$$
\begin{aligned}
& S G=\sum_{i=1}^{8} t_{i}\left(1+r_{i}\right)\left(\sum_{j=1}^{8} p_{j} a_{j i}+w 1_{i}\right) x_{i}+\sum_{i=1}^{4} r_{i}\left(P_{j} a_{j i}+\right. \\
& \left.+w 1_{i}\right) x_{i}+\sum_{j=1}^{\mathrm{VII}} q_{j} y_{j} \\
& -\left[\sum_{i=1}^{8}\left(P_{i}-e P i_{i}\right) z_{i}+\left(p^{*} p^{3}\right) x_{\mathrm{I}}+\sum_{i=1}^{8} g_{i}+w g+m g e+\sum_{j=2}^{\mathrm{VII}} T R_{j}+\right. \\
& \left.\sum_{i=1}^{r} \sum_{j=r}^{V I I} \quad S U B_{i j} c_{i j}\right]
\end{aligned}
$$




\section{Ahorro externo}

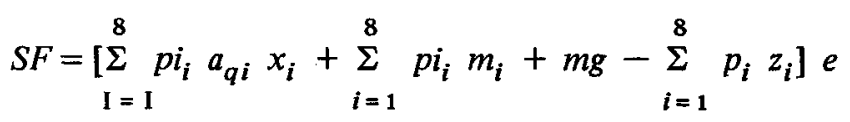

\section{Ahorro privado}

$S P=\sum_{j=1}^{8} Y_{j}\left(1-q_{j}\right) s_{j}$

\section{Equilibrio entre ahorro e inversión}

$$
\sum_{j=1}^{8}\left(d s_{i}+\mathrm{I}_{i}\right) P_{i}=S G+S F+S P
$$

Una descripción detallada del modelo, del método de cálculo de los parámetros y de la computación viene en Lustig, 1982 b.

\section{Cuadro A.1}

Resumen de las fórmulas del costo fiscal

Transferencia

de ingreso

Subsidio al precio

(discriminatorio)

$$
(1 / / F d) *[1+f]
$$

Subsidio al precio (generalizado)

$$
(1 / E d) *(1 / \partial) *\left[1+\left(E T d / E a^{\prime}\right) * g\right]
$$

Nota: $m$, propensión marginal al consumo; $k d$, elasticidad-precio de la demanda del grupo beneficiario; $f$, incremento porcentual requerido; $\partial$ proporción consumida por el grupo beneficiario; $E T d$, elasticidad-precio de la demanda del total de la población. 


\section{Cuadro A.2}

Clasificación de la encuesta de ingresos y gastos en clases sociales

\begin{tabular}{|c|c|c|c|c|}
\hline \multicolumn{2}{|c|}{ Clase social $^{1}$} & \multirow{2}{*}{$\frac{\text { Actividad }^{2}}{\text { Agrícola }}$} & \multirow{2}{*}{$\begin{array}{c}\begin{array}{c}\text { Posición } \\
\text { en la ocupación }\end{array} \\
\begin{array}{c}\text { Patrón } \\
\text { Trabajador por } \\
\text { cuenta propia }\end{array}\end{array}$} & \multirow{2}{*}{$\begin{array}{c}\text { Ingreso } \\
\mathrm{Y}<1 . \mathrm{S} . \mathrm{M} . \\
\mathrm{Y} \geqslant 1 . \mathrm{S} . \mathrm{M} .\end{array}$} \\
\hline 1) & Campesinos & & & \\
\hline 2) & Jornaleros & Agrícola & $\begin{array}{l}\text { Empleado } u \\
\text { obrero }\end{array}$ & $Y \geqslant 1 . S . M$. \\
\hline 3) & $\begin{array}{l}\text { Capitalistas } \\
\text { urbanos }\end{array}$ & Agrícola & Patrón & $Y \geqslant 1 . S . M$. \\
\hline 4) & $\begin{array}{l}\text { Asalariados } \\
\text { urbanos }\end{array}$ & Resto & $\begin{array}{c}\text { Empleado } u \\
\text { obrero }\end{array}$ & $Y \geqslant 1 . S . M$. \\
\hline 5) & $\begin{array}{l}\text { Capitalistas } \\
\text { no agrícolas }\end{array}$ & Resto & $\begin{array}{l}\text { Patrón } \\
\text { Trabajador por } \\
\text { cuenta propia }\end{array}$ & $Y \geqslant 1 . S . M$. \\
\hline 6) & Comerciantes & Comercio & $\begin{array}{l}\text { Patrón } \\
\text { Trabajador por } \\
\text { cuenta propia }\end{array}$ & $Y \geqslant 1 . S . M$. \\
\hline 7) & $\begin{array}{l}\text { Marginados } \\
\text { urbanos }\end{array}$ & $\begin{array}{l}\text { Resto y } \\
\text { comercio }\end{array}$ & $\begin{array}{c}\text { Patrón } \\
\text { Trabajador por } \\
\text { cuenta propia } \\
\text { Empleado u } \\
\text { obrero }\end{array}$ & $\begin{array}{l}Y<1 . S . M . \\
Y<1 . S . M . \\
Y<1 . S . M .\end{array}$ \\
\hline
\end{tabular}

1.S.M. = Un salario mínimo, \$2 700.00 al mes/hogar.

1 La clasificación se hizo con base en la actividad y posición en la ocupación del jefe del hogar.

2 Se consideraron como actividades agrícolas: agricultura, ganadería silvicultura y pesca; y como resto, cualquier otra actividad fuera de agricultura y comercio. 
LUSTIG: ANÁlISIS DE POLÍtICAS DE CONSUMO ALIMENTARIO 223

\section{Cuadro A.3}

Población por clase (en miles)

\begin{tabular}{lrr}
\hline & \multicolumn{1}{c}{ Personas } & \multicolumn{1}{c}{ Hogares } \\
\hline Campesinos & 9596.619 & 1573.374. \\
Jornaleros & 8908.581 & 1501.403 \\
Capitalistas agrícolas & 299.145 & 50.505 \\
Asalariados & 25548.386 & 4479.053 \\
Capitalistas no agrícolas & 5097.455 & 816.480 \\
Comerciantes & 3075.225 & 495.910 \\
Marginales urbanos & 7062.786 & 1544.730 \\
Total & 59582.197 & 10461.455 \\
\hline
\end{tabular}

Nota: il cálculo de estas cifras se hizo de la siguiente forma:

1a. estructura poblacional de la muestra de la Fncuesta de Ingresos y Gastos de 1977 (SPP), se aplicó a la población estimada para 1975, según datos del Consejo Nacional de Población. Dicha estructura se estimó con base en la clasificación de los hogares por clase social que aparece en el Cuadro A.2; el número de hogares por clase se multiplicó por el tamaño promedio del hogar (por clase) $y$, de esta manera, se obtuvo el total de personas (por clase).

\section{Cuadro A.4}

Propensiones marginales al consumo, elasticidad-precio y proporciones consumidas de alimentos procesados

\begin{tabular}{lccc}
\hline & $\begin{array}{c}\text { Propension } \\
\text { marginal al } \\
\text { consumo } / \mathrm{m})\end{array}$ & $\begin{array}{c}\text { Elasticidad } \\
\text { precio } \\
\text { (Ed, ETd) }\end{array}$ & $\begin{array}{c}\text { Proporción } \\
\text { consumida } \\
\text { (J) }\end{array}$ \\
\hline Campesinos & 0.3616 & -0.6961 & 0.0544 \\
Jomaleros & 0.3748 & -0.7194 & 0.0405 \\
\hline
\end{tabular}

Nota: til cálculo de estos coeficientes se hizo con información de la Encuesta Nacional de Ingresos y Gastos de los Hogares: 1977 (Secretaría de Programación y Presupuesto). I a metodología se describe en Lustig (1982c). 


\section{Bibliografía}

GibSON, R., LuSTig, N., y TAYlor, L., 1982a, "Impactos distributivos de las políticas del Sistema Alimentario Mexicano en un marco de equilibrio general", Distribución del ingreso en México. Ensayos, Subdirección de Investigación Económica y Bancaria, Banco de México, S. A., 1982.

1982b, Terms of Trade and Class Conflict in a Marxian Computable General Equilibrius Model for Mexico, Documentos de Trabajo, Centro de Estudios Económicos, El Colegio de México.

, 1982c, "Ventajas comparativas y autosuficiencia alimentaria: una comparación en un modelo de equilibrio general con dos especificaciones de precios", mimeo. Por publicar en Investigación Económica, Facultad de Economía, UNAM.

Instituto Nacional di: la Nutrición, 1979, Segunda Fncuesta Nacional de Alimentación, México.

MACCARTHY, D., 1978, "Food and Nutrition Planning: Pakistan", International Nutrition, Policy and Planning Program, Center for International Studies, MIT, Discussion Paper No. 12.

Lluch, Powell y Will!ams, 1977, Patterns in Household Demand, Demand and Saving, Oxford University Press, Londres.

Lustig, N., 1982a, "Distribución del ingreso y consumo de alimentos: estructura, tendencia y requerimientos distributivos a nivel nacional", Demografia y Economia, vol. XVI, núm. 50.

, 1982b, "Políticas de precios y subsidios del Sistema Alimentario Mexicano y distribución del ingreso", SINE/SAM, segundo reporte, agosto.

, 1983b, "Distribution of Income, Food Consumption and Fiscal Cost of Alternative Policy Options" en P. Aspe y P. Sigmund, The Political Economy of Income Distribution in Mexico, Harpers and Row, 1983.

Reutlinger, S. y Selowsky, M., 1976, Mainutrition and Poverty: Magnitude and Policy Options, John Hopkins University Press, Baltimore.

Reyes Heroles, J. F., 1980, "Welfare Effects of Short-Run Macroeconomic Policies in a Dual Economy: the Case of Mexico", tesis doctoral, Departamento de Economía, Massachusetts Institute of Technology.

Secretaría de Programación y Presupuesto, 1981, Encuesta Nacional de Ingresos y Gastos de los Hogares: 1977; Coordinación General del Sistema Nacional de Información; México.

TAYLOR, L. y colaboradores, 1980, Food subsidy programs: a survery, MIT, copia mimeo. 